\title{
Domestic violence among married couples during COVID-19 lockdown in an urban setting: A cross- sectional survey
}

\author{
V Kannappa Shetty ${ }^{1}$, S Priyanka ${ }^{2}$, M Sanjeev Kumar ${ }^{3}$, C Akhila $^{4}$, Jyothsna Sreenivas ${ }^{4}$, Vijaya Raghavan ${ }^{2}$
}

\begin{abstract}
Background: The ongoing COVID-19 pandemic and lockdown to reduce the spread of the infection has had a huge mental health impact. Added social and economic constraints to this could lead to violence among the married couples in the domestic settings. Hence, the aim of the study was to examine the gender differences in domestic violence and factors associated with it among married couples living together during COVID-19 lockdown in an urban setting.
\end{abstract}

Materials and Methods: Online survey through Google Forms was used to collect data from the study participants after obtaining written informed consent. Participants living with their partner during the lockdown were recruited into the study. Sociodemographic profile of the study participants was collected through a semi-structured proforma, Family emotional involvement and criticism scale, Brief COPE, The violence scale and P.G.I. General Wellbeing. All statistical analysis was done using SPSS 20.0.

Results: A total of 69 participants completed the survey. The mean age of the participants was $40.5 \pm 9.1$. More females $(45,65.2 \%)$ had participated in the study than males $(24,34.8 \%)$. Females were found to report statistically significant higher violence in sexual $(\mathrm{p}=0.019)$, social violence as ridiculed, demeaned or insulted in the presence of family members and friends $(\mathrm{p}=0.01)$ and intellectual violence by non-participation when issues are important $(\mathrm{p}=0.006)$. Multivariate logistic regression analysis showed female gender alone found to be associated with domestic violence among the study participants.

Conclusion: Domestic violence during COVID-19 lockdown has highlighted the prevailing gender-based violence and demands for interventions to prevent and reduce domestic violence at the individual, family, and society level.

Keywords: domestic violence, COVID-19, lockdown, sexual violence, women

Running Title: Physical comorbidities in psychiatric outpatients

Address for Correspondence: Dr. Vijaya Raghavan, Consultant Psychiatrist - Research, Schizophrenia Research Foundation, Chennai, Tamilnadu, India; E-mail: vijayaraghavan @scarfindia.org.

How to Cite this Article: Shetty VK, Priyanka S, Kumar S, Akhila C, Srinivas J, Vijaya Raghavan. Domestic violence among married couples during COVID-19 lockdown in an urban setting: A crosssectional survey. Indian Journal of Mental Health and Neurosciences.2020;3(2): pp 45-52

\section{INTRODUCTION}

OVID-19, which started as a seemingly harmless viral infection in the heart of China, took form as a pandemic in late 2019 and has continued to wreak havoc since then. India witnessed its first case of coronavirus infection on January $30^{\text {th }}, 2020$. The country has been reporting more new cases every day since March, 2020. A nation-wide lockdown that was announced in March 2020 to reduce the number of COVID-19 cases turned out to be detrimental to the economy as well as the people's mental well-being. ${ }^{1}$ This has given rise to several psychosocial issues like hysteria anxiety, depression, stress, phobic behaviour; economic issues among masses like loss of income, job, and closure of business to mention a few. ${ }^{2}$ These issues have

${ }^{1}$ Department of Psychiatric Social Work, Dharwad Institute of Mental Health and Neurosciences, Dharwad, Karnataka, India; ${ }^{2}$ Schizophrenia Research Foundation, Chennai, Tamilnadu, India; ${ }^{3}$ Centre for PSS in Disaster Management, National Institute of Mental Health and Neurosciences, Bengaluru, Karnataka, India; ${ }^{4}$ Abhaya Hospital, Wilson Garden, Bengaluru, Karnataka, India 
thrown open many challenges which the entire world is struggling to overcome.

Domestic violence is one of the most common crimes against women which is inextricably linked to patriarchy. Often referred to as intimate partner violence, it disproportionately affects women, with nearly one in three women victimized by physical or sexual violence through their lifetimes. ${ }^{3}$ The phenomenon of violence against women within the family in India is complex and deeply embedded. Women are subjected to violence not only from husbands but also from members of both the maternal and the marital home. The causal factors or contributing factors of domestic violence are countless. Studies show that perpetrators are generally arrogant and jealous of their partner. ${ }^{4-6}$ Education level, age, experiencing or witnessing violence during childhood, risky use of drugs or alcohol, personality disorders, previous history, low social and economic status of women, poverty, lack of women's civil rights, including restrictive or inequitable divorce and marriage laws, social acceptance of violence as a conflict resolution strategy are some of the other factors. Studies have also revealed that sons of violent parents, ${ }^{7}$ men raised in patriarchal family structure that encourages traditional gender roles are more likely to abuse their intimate partners. ${ }^{8}$ In 2018, over 16 women out of every 100000 across India experienced domestic abuse in some form. In the past few years, the number of these cases have gone down gradually.

Alongside COVID-19, domestic violence increased worldwide as a 'shadow pandemic'. With governments declaring lockdown, women living in abusive relationships were forced to stay home with their perpetrators putting them more at risk. ${ }^{9}$ As per the statistics released by the National Commission for Women (NCW) India, in early April 2020 there was $100 \%$ increase in complaints related to violence against women after the nationwide lockdown was imposed. ${ }^{10}$ In 2020, during the 68-day period between March 25 and May 31, women lodged 1,477 complaints of domestic violence, which was more than those received between March and May in the previous 10 years. About $86 \%$ women who experienced violence never sought help, and $77 \%$ of the victims did not even mention the incident to anyone. Among those who reached out, more than $90 \%$ of the victims sought help only from their immediate family. Unemployment, low incomes, lack of resources, and lack of social support are likely to be the reasons for rise in domestic violence cases during societal shutdowns. ${ }^{11}$
Very few studies from India have explored the pattern of domestic violence among males and females during COVID-19 lockdown. It is important to understand the impact of lockdown on domestic violence as it will help in developing appropriate interventions to prevent, reduce and treat such violence. Hence, the aim of the study was to estimate the differences in domestic violence by gender and factors associated with domestic violence among married couples living together during COVID-19 lockdown in an urban setting.

\section{MATERIALS AND METHODS}

Site: The study was conducted through online survey using Google Forms. All the questions were entered into the Google Forms and the link to the survey were shared with the potential participants through social media platforms and through personal contacts. Residents of Bengaluru city only were requested to participate in the study. The survey was kept open for a period of one month for respondents and was closed after that period. Institutional Ethics Committee (IEC) approval was obtained before the start of the study.

Study participants: The study was conducted among married couples during COVID-19 lockdown in Bengaluru, a cosmopolitan city in south India. For recruitment into the study, married couples living together during COVID-19 lockdown, both genders, above 18 years of age and residing in Bengaluru during the lockdown were included. Married but living separately during lockdown and not willing provide written informed consent were excluded from the study.

Measures: All the assessments were administered online through Google Forms. It took around 30-45 minutes to complete the survey. Snowballing sampling was used to recruit participants for the survey from the city of Bangalore. Reminders were sent twice (start of second and fourth week) for all the participants during the one month when the survey was open to the respondents.

\section{Assessments:}

Socio-demographic variables: A semi-structured proforma was developed to collect the sociodemographic profile of the study participants such as age, gender, and education.

Expressed emotion: Family emotional involvement and criticism scale (FEICS) ${ }^{12}$ is a 14 item scale which measures two dimensions of expressed emotion (EE), namely emotional over involvement (EI) and perceived criticism (PC) in the family. This scale proposes that 
$\mathrm{EE}$ is an important variable in measuring and treating both bio-psychological distresses. On 14 item scale, the perceived criticism subscale would clearly point out negative attitudes and emotional over involvement scale clearly reveal high levels of emotional involvement. The 14 items are structured such that perceived criticism is measured by even-numbered items and emotional over involvement is assessed by odd numbered items. A 5 point Likert type scale includes response options of almost never, once in a while, some, often, almost always. On this scale high scores indicate greater levels of perceived criticism and emotional over involvement.

Coping strategies: The Brief COPE is a coping inventory developed by Carver, $1997 \cdot{ }^{13}$ It is a brief measure modified from the COPE (Carver, Scheier, \& Weintraub, 1989), ${ }^{14}$ assessing several responses known to be relevant to the effective and ineffective coping. Examples of coping scales include denial, active coping and behavioural disengagement. It consists of 28 items and 14 sub scales rated on a scale of $0,1,2,3$. There is no negative scoring and the higher the score the better the coping.

\section{Outcome variable}

Violence: The violence scale was developed by Bhatti. ${ }^{15}$ This tool has often been used in researches on violence as a screening instrument to assess the pattern of violence since it has only demonstration for logical validation, face validity and also content validity. The original violence screening tool developed by Bhatti consists of five broad areas for assessing patterns of violence namely Physical violence (15 items), Verbal violence (2 items), Social violence (5 items), Emotional violence (5 items) and Intellectual violence (5 items) and sexual violence is included in emotional violence. Here, the description of various types of violence are as follows: 1 . Physical violence refers to family violence by use of means such as beating, kicking, pushing and so on; 2. Verbal violence refers to means such as use of abusive language and threats that family uses; 3 . Sexual violence refers to means such as forced sex or deprivation of sex or any act sexual in nature performed without consent or understanding; 4. Social violence refers to the demeaning or disrespectful acts shown to family members in social situations; 5. Emotional violence refers to the intentional deprivation of love, sympathy, affection or care by family members; and 6 . Intellectual violence refers to wilful non-participation in discussions of importance, excusing oneself from such discussions.
General Wellbeing: General wellbeing was assessed by a 20 -item scale was called PGI General Well-being scale by Wig, Pershad and Verma, in 1983. ${ }^{16}$ This scale measures subjective well-being (Positive mental health). The maximum score is 20 . This scale can be administered to all educational levels and orally to illiterates, and takes about 5-8 minutes of reporting. The scoring was achieved by counting the number of affirmative scores with scores ranging from 0 to 20 . This was classified further as 0 to 6.5 is poor wellbeing, 6.6 to 13 is moderate wellbeing and 13.1 to 20 is good wellbeing.

\section{Statistical analysis}

All statistical analysis was computed using SPSS 20.0. Descriptive statistics was used to describe the study variables; mean and standard deviation was used for continuous variables and frequency and percentage were used for categorical variables. Association between categorical variables were examined using chi-square test while the continuous variables were assessed for association using Pearson's correlation. Logistic regression analysis was used to identify the factors associated with domestic violence. The statistical significance was represented by p-value and $95 \%$ confidence interval. A p-value of $<0.05$ was set as significance.

\section{RESULTS}

\section{Socio-demographic profile of the participants}

The mean age of the study participants was $40.5 \pm 9.1$. More females $(45,65.2 \%)$ had participated in the study than males $(24,34.8 \%)$. While most of the sociodemographic profile of the male and female participants were comparable, annual income of the female participants were significantly lower $(p=0.02)$ when compared with male participants (Table 1).

Expressed emotion and coping strategies among study participants

The mean perceived criticism was found to be $29.8 \pm 7.5$ and the emotional overinvolvement was found to be 16.4 \pm 3.9 . The mean scores for avoidant and approach coping strategies were $24.0 \pm 5.6$ and $33.7 \pm 6.9$, respectively. There were no gender differences in the scores of expression emotion and coping strategies (Table 1).

Table 1: Comparison of socio-demographic, expression emotion and coping strategies between males and females among the study participants $(\mathrm{N}=69)$ 


\begin{tabular}{|c|c|c|}
\hline Variable & $\begin{array}{c}\text { Male }(\mathrm{N}=24) \\
\mathrm{N}(\%) ; \text { Mean } \pm \text { SD }\end{array}$ & $\begin{array}{c}\text { Female }(\mathrm{N}=45) \\
\mathrm{N}(\%) \text {; Mean } \pm \text { SD } \\
\end{array}$ \\
\hline Age & $40.8 \pm 9.1$ & $40.4 \pm 9.3$ \\
\hline $\begin{array}{l}\text { Education } \\
\text { PUC } \\
\text { Degree } \\
\text { Professional degree }\end{array}$ & $\begin{array}{c}1(4.2) \\
7(29.2) \\
16(66.6) \\
\end{array}$ & $\begin{array}{c}1(2.2) \\
10(22.2) \\
34(75.6) \\
\end{array}$ \\
\hline $\begin{array}{l}\text { Occupation } \\
\text { Government } \\
\text { Private } \\
\text { Business } \\
\text { Unemployed } \\
\text { Homemaker }\end{array}$ & $\begin{array}{c}4(16.7) \\
16(66.7) \\
3(12.5) \\
1(4.2) \\
0(0)\end{array}$ & $\begin{aligned} & 10(22.2) \\
& 20(44.4) \\
& 3(6.7) \\
& 2(4.4) \\
& 10(22.2) \\
&\end{aligned}$ \\
\hline Annual income (in lakhs) & $11.7 \pm 9.6$ & $6.4 \pm 8.4$ \\
\hline Duration of marriage (in years) & $11.1 \pm 8.6$ & $14.8 \pm 9.7$ \\
\hline $\begin{array}{l}\text { History of mental illness } \\
\text { No } \\
\text { Yes }\end{array}$ & $\begin{array}{c}23(95.8) \\
1(4.2)\end{array}$ & $\begin{array}{c}43(95.6) \\
2(4.4)\end{array}$ \\
\hline $\begin{array}{l}\text { Physically challenged } \\
\text { No } \\
\text { Yes }\end{array}$ & $\begin{array}{c}23(95.8) \\
1(4.2)\end{array}$ & $\begin{array}{c}45(100) \\
0(0)\end{array}$ \\
\hline $\begin{array}{l}\text { Expressed emotion } \\
\text { Perceived criticism } \\
\text { Emotional overinvolvement }\end{array}$ & $\begin{array}{l}29.2 \pm 8.6 \\
16.1 \pm 4.5\end{array}$ & $\begin{array}{l}30.1 \pm 6.9 \\
16.5 \pm 3.6\end{array}$ \\
\hline $\begin{array}{l}\text { Coping strategy } \\
\text { Approach } \\
\text { Avoidant }\end{array}$ & $\begin{array}{l}31.9 \pm 7.4 \\
23.5 \pm 5.3\end{array}$ & $\begin{array}{l}34.7 \pm 6.5 \\
24.3 \pm 5.8\end{array}$ \\
\hline
\end{tabular}

Differences in domestic violence based on gender among the study participants

Sexual violence was found to be significantly higher among the female participants ( $\mathrm{p}=0.019)$ when compared with male participants. Also, female participants were found to have higher prevalence of social violence as ridiculed, demean or insulted in the presence of family members and friends $(\mathrm{p}=0.01)$ and intellectual violence by nonparticipation when issues are important $(\mathrm{p}=0.006)$ (Table 2). No statistically significant differences were observed in the prevalence of other forms of domestic violence among male and female participants.

Table 2: Comparison of violence between males and females among the study participants $(\mathrm{N}=69)$

\begin{tabular}{|l|c|c|c|}
\hline \multicolumn{1}{|c|}{ Violence } & $\begin{array}{c}\text { Male (N=24) } \\
\text { Present - N(\%) }\end{array}$ & $\begin{array}{c}\text { Female (N=45) } \\
\text { Present - N(\%) }\end{array}$ & p-value \\
\hline Physical & & & \\
Pushing & $1(4.2)$ & $8(17.8)$ & 0.11 \\
Slapping & $1(4.2)$ & $9(20)$ & 0.07 \\
Punching & $2(8.3)$ & $7(15.6)$ & 0.39 \\
Sexual & $0(0)$ & $9(20)$ & 0.01 \\
\hline Verbal & & & \\
Use of abusive and filthy language & $5(20.8)$ & $9(20)$ & 0.94 \\
Verbal threatening of dire consequences & $1(4.2)$ & $10(22.2)$ & 0.05 \\
\hline
\end{tabular}




\begin{tabular}{|c|c|c|c|}
\hline $\begin{array}{l}\text { Social } \\
\text { In the public place } \\
\text { In the presence of family members and friends }\end{array}$ & $\begin{array}{c}3(12.5) \\
1(6.7)\end{array}$ & $\begin{array}{c}7(15.6) \\
14(31.1)\end{array}$ & $\begin{array}{l}0.73 \\
0.01\end{array}$ \\
\hline $\begin{array}{l}\text { Emotional or psychological } \\
\text { Deprived of love and affection } \\
\text { Deprived of care and sympathy }\end{array}$ & $\begin{array}{l}2(8.3) \\
2(8.3)\end{array}$ & $\begin{array}{l}11(24.4) \\
12(26.7)\end{array}$ & $\begin{array}{l}0.10 \\
0.07\end{array}$ \\
\hline $\begin{array}{l}\text { Intellectual } \\
\text { Non participation when issues are important } \\
\text { Not having stimulating exchange of ideas }\end{array}$ & $\begin{array}{c}2(8.3) \\
6(16.7)\end{array}$ & $\begin{array}{c}18(40) \\
13(28.9)\end{array}$ & $\begin{array}{c}0.006 \\
0.26\end{array}$ \\
\hline
\end{tabular}

Factors associated with sexual violence among the study participants

Univariate and multivariate analysis showed that no socio-demographic variables, expression emotion and coping strategies were associated with domestic violence except female gender $(\mathrm{p}=0.02)$ (Table 3).

Table 3. Multivariate logistic regression analysis of factors associated with sexual violence among the study participants $(\mathrm{N}=69)$

\begin{tabular}{|l|c|c|c|}
\hline \multicolumn{1}{|c|}{ Variable } & Odds ratio (OR) & OR 95\%CI & p-value \\
\hline Age & 1.303 & $-0.15-0.69$ & 0.22 \\
\hline Gender & & & \\
Male & Reference & & 0.02 \\
Female & 4.46 & $2.34-6.43$ & 0.29 \\
\hline Annual income & 1.098 & $-0.08-0.26$ & 0.13 \\
\hline Duration of marriage & 0.69 & $-0.85-0.10$ & \\
\hline Education & & & 1 \\
PUC & Reference & & 0.99 \\
Degree & 1.34 & $-36137.15-36137.73$ & \\
Professional degree & 1.25 & $-34526.74-34564.01$ & 0.64 \\
\hline Occupation & & & 0.49 \\
Government & Reference & & 0.99 \\
Private & 0.56 & $-3.04-1.85$ & 0.86 \\
Business & 4.46 & $-2.71-5.71$ & \\
Unemployed & 5.05 & $-26531.48-26493.27$ & 0.306 \\
Homemaker & 0.78 & $-3.02-2.50$ & 0.284 \\
\hline Expressed emotion & & & \\
Perceived criticism & 0.47 & $-2.21-0.69$ & 0.66 \\
Emotional overinvolvement & 4.68 & $-1.28-4.37$ & 0.65 \\
\hline Coping strategy & & & \\
Approach & 0.95 & $-0.27-0.16-0.28$ & \\
Avoidant & 1.05 & & \\
\hline
\end{tabular}

General wellbeing and factors associated with it among the study participants

The mean wellbeing score among the study participants was 13.6 \pm 3.5 . No statistical difference was found between males and females with respect to general wellbeing scores $(\mathrm{p}=0.579)$. Linear regression analysis showed that general wellbeing is inversely associated with avoidant type of coping strategy ( $\mathrm{p}=0.022 ; 95 \% \mathrm{CI}=-0.35$ to -0.03 ). It was not found to be associated with expression emotion and domestic violence (Table 4). 
Table 4 Multivariate linear regression analysis of factors associated with general wellbeing among the study participants $(\mathrm{N}=69)$

\begin{tabular}{|l|c|c|c|}
\hline \multicolumn{1}{|c|}{ Variable } & t-statistic & $\mathbf{9 5 \% C I}$ & p-value \\
\hline Age & 1.42 & $-0.06-0.37$ & 0.16 \\
\hline Annual income & 0.34 & $-0.08-0.12$ & 0.74 \\
\hline Duration of marriage & -0.48 & $-0.26-0.16$ & 0.63 \\
\hline Expressed emotion & & & \\
Perceived criticism & 0.91 & $-0.45-1.18$ & 0.37 \\
Emotional overinvolvement & -0.89 & $-2.23-0.85$ & 0.37 \\
\hline Coping strategy & & & \\
Approach & 1.57 & $-0.02-0.23$ & 0.12 \\
Avoidant & -2.34 & $-0.35--0.02$ & 0.03 \\
\hline
\end{tabular}

\section{DISCUSSION}

The aim of the study was to explore the differences in domestic violence among males and females living with their partners during COVID-19 lockdown and factors associated with it.

Results indicate that women were significantly more subjected to sexual violence, social violence and intellectual violence when compared with men during the COVID-19 lockdown. Though the literature on domestic violence during COVID-19 is sparce, many media coverage and reports from independent organizations have shown similar results to this study. A recent study from Bangladesh has highlighted the increased sexual violence against women is increasing in times of COVID-19. ${ }^{17}$ Similarly, in Jianli County, Hubei province of China, a police department reported a tripling of domestic violence cases in February 2020 compared with February 2019, estimating that $90 \%$ were related to the COVID-19 epidemic. ${ }^{18}$ Various factors contribute to this increased violence against women during this COVID-19 pandemic: the aggressor's increased stress due to fear of falling ill, uncertainty about the future, impossibility of social contact, the imminent threat of reduced income (especially in the underprivileged classes, where a large proportion make their living from informal labor), and the consumption of alcoholic beverages and other psychoactive substances. ${ }^{19}$ Also, the increase in the violence against women was seen during past epidemics such as Ebola ${ }^{20}$ and Zika. ${ }^{21}$

Other than female gender, no socio-demographic, expressed emotion or coping strategies were found to be associated with sexual violence in the study population. Previous studies from south India has identified various factors to be associated with sexual violence such as husbands' primary education, employment as drivers, alcohol consumption, and having multiple sex partners. ${ }^{22}$ This could be due to the fact that many other variables associated with domestic violence was not included in the current study. Also, domestic violence is attributed to household work related disparity in India, largely a patriarchal society, and domestic work is primarily considered women's job. Absence of domestic help and people thrown into close quarters, increases workload and cabin fever ensues, adding fuel to the ongoing friction between the couple and results in increased chances of domestic violence. ${ }^{23}$ Similar to the findings in this study, previous study from India has indicated women's use of safety and avoidance strategies are safety behaviors that play a key role in maintaining women's fear and societal dynamics. ${ }^{24}$

As everyone was asked to stay at home during the COVID-19 pandemic, this has increased the risk of intimate partner violence, especially among women who are already in such relationships. Moreover, the COVID-19 pandemic restrictions isolated the women from seeking help or reaching for resources to fight against domestic violence. ${ }^{25}$ This highlights the need for the effective implementation of The Protection of Women from Domestic Violence Act, 2005 in such crucial times. ${ }^{26}$ Awareness about domestic violence and resources available to fight against should be widely disseminated through traditional and electronic mass media. $^{27}$

This study is not without limitations. 1. Small sample size; 2. Data collection from only one urban site makes it less generalizable to other urban and rural settings in India; 3 . Since the study used online survey methodology to collect data, it would have led to sampling bias as only people with access to internet and able to read English taking part in the study, excluding others; 4. Respondent bias is possible as people who were the victims of violence could have responded than people who are not victims; and 5. Various established factors 
associated with domestic violence such as substance use and attitudes are not measured which be cofounders in assessing association between violence and COVID-19.

Future research should investigate collecting more representative samples from different parts of India, both rural and urban settings to generalize on the domestic violence in Indian households during pandemics and other disasters. Appropriate interventions should be designed and tested through studies to find scalable strategies to prevent domestic violence. Policy level changes should be enacted to protect the vulnerable population from domestic violence in India.

\section{Acknowledgement: None}

Source of funding: this research has not received specific financial grant from any funding agency in the public, commercial or not-for-profit sectors

Conflict of interest: The authors have declared no conflict of interest with respect to the research, authorship, and/or publication of this article.

\section{REFERENCES}

1 Golechha M. COVID-19, India, lockdown and psychosocial challenges: What next? International Journal of Social Psychiatry. 2020; doi.org/10.1177/0020764020935922. (ePub ahead of Print)

2 Dubey S, Biswas P, Ghosh R, et al. Psychosocial impact of COVID-19. Diabetes \& Metabolic Syndrome. Clinical Research \& Reviews. 2020; doi: 10.1016/j.dsx. 2020.05.035. (ePub ahead of Print)

3 Gulati G, Kelly BD. Domestic violence against women and the COVID-19 pandemic: What is the role of psychiatry? International Journal of Law and Psychiatry. 2020:101594. doi.org/10.1016/j.ijlp.2020.101594. (ePub ahead of Print)

4 Jewkes R, Levin J, Penn-Kekana L. Risk factors for domestic violence: findings from a South African crosssectional study. Social Science and Medicine.2002;55(9):1603-1617

5 Abramsky T, Watts $\mathrm{CH}$, Garcia-Moreno $\mathrm{C}$, et al. What factors are associated with recent intimate partner violence? Findings from the WHO multi-country study on women's health and domestic violence. BMC Public Health. 2011;11(1):109.

6 Santhosh K. A Review on the perpetrators of child abuse. Review of Social Sciences. 2016;1(3):45-52

7 Martin SG. Children exposed to domestic violence: Psychological considerations for health care practitioners. Holistic Nursing Practice. 2002;16(3):7-15

8 Fagot BI, Pears KC, Capaldi DM, et al. Becoming an adolescent father: precursors and parenting. Developmental Psychology. 1998;34(6):1209-1219

9 Mehta B, Sharma MMJ, Sam ME. Home is where the Hurt is! The Impact of COVID-19 Lockdown on Women in India. International Journal of Innovation, Creativity and Change. 2020;14(6):330-352

10 Singh S, Bhattacharyya R. A Review of Domestic Violence against Women in India during Lockdown. International Journal of Innovation, Creativity and Change. 2020;14(6):230-242

11 Thomas MW, Rajan SK. Intimate Partner Violence (IPV) in the wake of COVID-19 in India: a conceptual overview. The International Journal of Indian Psychology. 2020;8(2):1133-1138

12 Shields CG, Franks P, Harp JJ, et al. Development of the family emotional involement and critcism scale (feics): A self-report scale to measure expressed emotion. Journal of Marital and Family Therapy. 1992;18(4):395407 
13 Carver CS. You want to measure coping but your protocol'too long: Consider the brief cope. International Journal of Behavioral Medicine. 1997;4(1):92-100

14 Carver CS, Scheier MF, Weintraub JK. Assessing coping strategies: a theoretically based approach. Journal of Personality and Social Psychology. 1989;56(2):267-283

15 Bhatti RS, George TS. The measurement of family violence. Indian Journal of Social Work. 2001;62:347-366

16 Verma SK, Dubey BL, Gupta D. PGI General Well Being Scale: Some correlates. Indian Journal of Clinical Psychology. 1983;10:299-304

17 Sifat RI. Sexual violence against women in Bangladesh during the COVID-19 pandemic. Asian Journal of Psychiatry. 2020;54:102455

18 Allen-Ebrahimian B. China's Domestic Violence Epidemic, Axios. Online news article (accessed April 7, 2020) www.axios.com/china-domestic-violencecoronavirusquarantine -7b00c3ba-35bc-4d16-afddb76ecfb28882.html

19 Marques ES, Moraes CLd, Hasselmann MH, et al. Violence against women, children, and adolescents during the COVID-19 pandemic: overview, contributing factors, and mitigating measures. Cadernos de Saude Publica. 2020;36(4):e00074420

20 Onyango MA, Resnick K, Davis A, et al. Gender-Based Violence Among Adolescent Girls and Young Women: A Neglected Consequence of the West African Ebola Outbreak from 'Pregnant in the Time of Ebola' by Shwartz DA et al (Eds). Springer Publishing; 2019; pp:121-132

21 Cepeda Z, Arenas C, Vilardo V, et al. Dominican Republic Gender Analysis: A study of the impact of the Zika virus on women, girls, boys and men. @ Oxfam International April 2017:pp1-40

22 Chibber KS, Krupp K, Padian N, et al. Examining the determinants of sexual violence among young, married women in Southern India. Journal of Interpersonal Violence. 2012;27(12):2465-2483

23 Engage E. COVID-19, domestic abuse and violence: Where do Indian women stand. EPW Engage. 2020. Online article acccessed from www.epw.in/engage/article/covid-19-domestic-abuse-and-violence-where-do

24 Nieder C, Muck C, Kärtner J. Sexual Violence Against Women in India: Daily Life and Coping Strategies of Young Women in Delhi. Violence against Women. 2019;25(14):1717-1738

25 Roesch E, Amin A, Gupta J, et al. Violence against women during covid-19 pandemic restrictions. BMJ (Clinical Research ed.). 2020.m1712

26 Vora M, Malathesh BC, Das S, et al. COVID-19 and domestic violence against women. Asian Journal of Psychiatry. 2020;53:102227

27 Kaur R, Garg S. Addressing domestic violence against women: An unfinished agenda. Indian Journal of Community Medicine. 2008;33(2):73-76 